\title{
Teratogenic effect of isotretinoin in both fertile females and males (Review)
}

\author{
CARMEN-CRISTINA DRAGHICI ${ }^{1,2}$, RALUCA-GABRIELA MIULESCU ${ }^{1,3}$, RĂZVAN-COSMIN PETCA $^{4,5}$, \\ AIDA PETCA $^{6,7}$, MIHAI CRISTIAN DUMITRAȘCU ${ }^{6,8}$ and FLORICA ȘANDRU ${ }^{1,9}$ \\ ${ }^{1}$ Department of Dermatology, 'Elias' Emergency University Hospital, 011461 Bucharest; Departments of \\ ${ }^{2}$ Physioplogy, ${ }^{3}$ Farmacology and ${ }^{4}$ Urology, 'Carol Davila' University of Medicine and Pharmacy, 050474 Bucharest; \\ ${ }^{5}$ Department of Urology, 'Prof. Dr. Theodor Burghele' Clinical Hospital, 061344 Bucharest; ${ }^{6}$ Department of Obstetrics \\ and Gynecology, 'Carol Davila' University of Medicine and Pharmacy, 050474 Bucharest; \\ ${ }^{7}$ Department of Obstetrics and Gynecology, 'Elias' Emergency Hospital, 011461 Bucharest; ${ }^{8}$ Department of Obstetrics \\ and Gynecology, University Emergency Hospital of Bucharest, 050098 Bucharest; ${ }^{9}$ Department of Dermatology, \\ 'Carol Davila' University of Medicine and Pharmacy, 050474 Bucharest, Romania
}

Received November 2, 2020; Accepted December 2, 2020

DOI: $10.3892 /$ etm.2021.9966

\begin{abstract}
Isotretinoin is an oral derivate of vitamin A that has been used since 1982 for the treatment of multiple dermatologic conditions such as severe acne, rosacea, scarring alopecia, ichthyosis or non-melanoma skin cancer prophylaxis. The recommended dose is $0.5-1 \mathrm{mg} / \mathrm{kg} / \mathrm{day}$ for a period of 4-6 months in sebaceous gland pathologies. There are many adverse effects caused by isotretinoin but by far the most important is the teratogenicity induced by this drug which is estimated to have a $20-35 \%$ risk to infants that are exposed to isotretinoin in utero and includes numerous congenital defects such as craniofacial defects, cardiovascular and neurological malformations or thymic disorders. Isotretinoin induces apoptosis and cell cycle arrest in human sebocytes, emphasizing these as processes associated with its teratogenic effect. The aim of this review is to analyze the latest literature data regarding the teratogenic effect of isotretinoin for both fertile females and males and its biological effects underlying the occurrence of congenital malformations under the influence of isotretinoin.
\end{abstract}

Correspondence to: Dr Mihai Cristian Dumitrascu, Department of Obstetrics and Gynecology, University Emergency Hospital of Bucharest, 169 Splaiul Independentei, 050098 Bucharest, Romania E-mail: carmen.draghici3@gmail.com

Abbreviations: FDA, Food and Drug Administration; TRAIL, tumor necrosis factor-related apoptosis-inducing ligand; NGAL, neutrophil gelatinase-associated lipocalin; FoxO, forkhead box protein O; IGF-1, insulin growth factor-1; ATRA, all-trans retinoic acid; IGFBP3, insulin-like growth factor-binding protein 3; RXR $\alpha$, retinoid X receptor- $\alpha$; RAR $\alpha$, retinoic acid receptor- $\alpha$

Key words: isotretinoin, teratogenicity, apoptosis, acne, malformations

\section{Contents}

1. Introduction

2. Research methodology

3. Mechanism of action of isotretinoin

4. Dosage

5. Teratogenic effect of isotretinoin

6. Apoptosis and teratogenicity

7. Conclusions

\section{Introduction}

Isotretinoin or 13-cis-retinoic acid is an oral derivate of vitamin A that is used in the treatment of numerous dermatologic diseases such as ichthyosis, hidradenitis suppurativa, rosacea, scarring alopecia, non-melanoma skin cancer prophylaxis, but mainly used in sebaceous gland pathology (1).

The use of isotretinoin was investigated by Werner Bollag starting in 1960 as a treatment for skin cancer (2). It was revealed that isotretinoin was ineffective in skin cancer therapy, but useful for the management of acne vulgaris. Due to its numerous side effects, the drug was not used until 1975 when a series of clinical studies outlined its efficacy in treating cystic acne. As a result, isotretinoin was released to the market in 1982, in the USA by Hoffman-La Roche as a revolutionary treatment for severe and refractory acne vulgaris. It was the first drug capable of inducing partial or complete remission of the disease and for maintenance (2). Despite these results, many controversies have arisen regarding this treatment, most of them in the light of its side effects (2). Isotretinoin can cause several side effects, but by far the most important is teratogenicity. Other side effects include mucocutaneous dryness, increases in transaminases, hypertriglyceridemia, all of them manageable by the attending physician. There are also rare side effects such as inflammatory bowel diseases or depression which are still in debate $(3,4)$. 
Isotretinoin is an extremely useful treatment for acne due to its influences on many etiological factors involved in acne by affecting cellular differentiation, cell cycle progression, cell survival and apoptosis (5-7). As a result of all of these biologic mechanisms, it has been established that a dose of $0.5-1.0 \mathrm{mg} / \mathrm{kg} /$ day for a period of $4-6$ months is enough to produce a reduction in sebum excretion by $90 \%$ within a period of 6 weeks (5).

\section{Research methodology}

We analyzed the studies published in international journals in the last 20 years and found in the PubMed database, regarding the mechanism of actions of isotretinoin and its side effects. Isotretinoin is a controversial drug that is associated with many pathologies considered to be induced by its use, thus a rigorous research of the latest clinical studies was made in order to help the readers to become familiarized with this drug.

\section{Mechanism of action of isotretinoin}

Isotretinoin is considered to be the most efficient drug indicated for the treatment of severe forms of acne vulgaris and mainly, due to its strong sebum-suppressive effects, which is induced primarily from sebocyte apoptosis. The apoptosis effect generated by isotretinoin is also the basis for its use in the treatment of childhood neuroblastoma, promyelocytic leukemia or basal cell carcinoma. It also induces apoptosis in adult T-cell leukemia cells, B16F-10 melanoma cells, primary human keratinocytes, or Dalton lymphoma ascites cells (7).

There are many studies that have been conducted to analyze the mechanism of action of isotretinoin and some have succeeded to explain these physiopathological pathways. Nelson et al demonstrated that isotretinoin is responsible for inducing apoptosis and cell cycle arrest in human SEB-1 sebocytes, but also that apoptotic protein tumor necrosis factor-related apoptosis-inducing ligand (TRAIL) and neutrophil gelatinase-associated lipocalin (NGAL) contributes to the apoptotic effect of isotretinoin in the human sebaceous gland (8-10). The role of TRAIL and NGAL was confirmed also by Kelhälä et al who showed the increased expression of these two molecules in the skin of acne patients who were under treatment with isotretinoin (11). TRAIL has been found to induce apoptosis in several tumor cell lines but studies have shown that it is relatively non-toxic to normal cells, being constitutively expressed in many human tissues (11). In healthy patients, nuclear transcription factor, forkhead box protein $\mathrm{O}$ (FoxO) is responsible for inducing TRAIL expression and especially by FoxO3a $(12,13)$. In patients with acne, FoxO activity is under the control of growth factor signaling. This explains the fact that insulin growth factor-1 (IGF-1) and insulin, which are both increased in puberty or in patients with hyperglycemic diets or based on excessive dairy consumption, can induce FoxO phosphorylation by stimulating the kinase Akt followed by nuclear FoxO inactivation through cytoplasmic sequestration via 14-3-3 binding (14-20). Isotretinoin is isomerized in sebocytes to all-trans retinoic acid (ATRA) (21). ATRA is responsible for upregulating the expression of FoxO3a, a key transcription factor of apoptosis, and TRAIL $(6,22,23)$. Studies have underlined that TRAIL is upregulated in the sebaceous gland of patients with acne that are being treated with isotretinoin, suggesting that this drug can increase FoxO/TRAIL signaling in these sebaceous glands, resulting in the apoptosis of sebocytes. The result of this process is the suppression of sebum, this being the most important anti-acne action of systemic isotretinoin treatment in patients with acne (7-10).

IGF-binding protein-3 (IGFBP3) is another FoxOdependent pro-apoptotic protein which is upregulated by isotretinoin treatment and is increased in human sebocytes during the treatment with isotretinoin. IGFBP3 is a nuclear transcription factor that interacts with retinoid $\mathrm{X}$ receptor- $\alpha$ $(\mathrm{RXR} \alpha)$ and retinoic acid receptor- $\alpha(\operatorname{RAR} \alpha)$ (24-26). Thereby, the interaction between RXR and IGFBP3 takes part in the transcriptional activity of $\operatorname{RXR} \alpha$, mediating the effects of IGFBP3 on cellular apoptosis (27). The activation of RAR $\alpha$ because of FoxO-dependent induction of nuclear IGFBP3 may overexpress the apoptotic NGAL (28). All of these findings are substantial proof that underline the role of isotretinoin in increasing the expression of pro-apoptotic proteins (FoxO, TRAIL, IGFBP3, NGAL).

\section{Dosage}

The common treatment scheme for acne vulgaris consists of $0.5-1 \mathrm{mg} / \mathrm{kg} / \mathrm{day}$ of isotretinoin for almost 16-30 weeks, depending on the severity of the disease. The response due to sebum reduction is shown after 6 weeks. Studies have shown that relapse is minimized when the total amount of treatment is at least $120 \mathrm{mg} / \mathrm{kg}$, but there are not necessarily any added benefits when the dose of isotretinoin is approximately $150 \mathrm{mg} / \mathrm{kg}$ (29). The half time of isotretinoin is approximately $22 \mathrm{~h}$ and the biovitality is $25 \%$. The European Directive recommends an initial dose of isotretinoin to be $0.5 \mathrm{mg} / \mathrm{kg} / \mathrm{day}$, for severe acne (nodular, conglobate) that is not responding to appropriate antibiotics and topical therapy (30). Isotretinoin is not indicated for children under 12 years of age and not as a first therapy line. The baseline investigations should be performed as before but also at 1 and 3 months throughout the treatment and all forms of peeling and wax depilation should be avoided during therapy and 6 months afterwards. All women in the fertile period are advised to have one or two contraceptive measures. These rules were made in order to prevent the possible side effects including pregnancy (31).

\section{Teratogenic effect of isotretinoin}

The teratogenic effect induced by isotretinoin has been described since 1982 when the drug was released on the market. The manufacturer of isotretinoin indicated the possible side effects known at that time, including teratogenicity, in a brochure used for patient education. In 1988, the pregnancy prevention program during isotretinoin treatment included 2 methods of contraception and monthly pregnancy tests to avoid pregnancies during the treatment with isotretinoin $(2,31)$. The risk of teratogenicity in infants exposed to isotretinoin in utero is estimated to be $20-35 \%$. This includes numerous congenital defects including craniofacial defects, cardiovascular and neurological malformations, or thymic disorders. Along with this, neurocognitive impairments even 
in the absence of any physical defects has been established to be $30-60 \%$ in children exposed to isotretinoin during the prenatal period (29).

Since it was released on the market, there have been a series of national programs in the USA and Canada to prevent pregnancy during treatment with isotretinoin. The first program was introduced in 1988 in Canada and included notifying women of the possible side effects that this drug could have on infants and obtaining their written agreement to use 2 methods of contraception in parallel and have monthly pregnancy tests. After 7 years, this program was proven to be inefficient (32). In 2002, another program, the USA-SMART (System to Manage Accutane-Related Teratogenicity) which consisted of 2 consecutive pregnancy tests with negative results at the beginning of the treatment and a voluntary registration to a database system. This program proved to be insufficient in pregnancy prevention (33-37).

In 2006, the US-FDA introduced iPLEDGE, a program designed to provide a more elaborate guideline for better prevention of an eventual pregnancy during isotretinoin treatment. It consists of monthly pregnancy tests, documentation of contraceptive methods and constant information regarding the possible side effects in order to reinforce the key message. Along with this, all patients were included in a database. All of these measures did not solve the pregnancy problem during the treatment period with isotretinoin and did not show better results when compared with the SMART program (33-37).

In order to improve iPLEDGE program, a series of measures should be employed including a better period of educational sessions for both women and their counterparts, regarding the treatment with isotretinoin and the possible side effects that it could have on infants, but also the possible contraceptive methods and how to perform proper pregnancy tests. In addition, the drug cannot be purchased without a medical prescription and in this way, there is an awareness regarding the efficiency of iPLEDGE (33-37).

In Europe, the European FDA in association with the European Directive concerned with systemic isotretinoin prescription implemented a pregnancy prevention program for all female patients under isotretinoin treatment. In this program, female patients are advised to use at least one contraceptive method but ideally should consider two methods of contraception including a barrier method and another effective method of contraception for 1 month before the first administration of oral isotretinoin, during the entire period of treatment and one month after stopping it. The patients are advised to perform several pregnancy tests, one pre-therapy, during therapy and 5 weeks post-therapy (38).

In 2017, Salih published a study regarding the effects of isotretinoin on intrauterine prenatal development in pregnant mice and outlined that administration of this drug from the first day of gestation induced the loss of appetite, slow physical activity, and skin and hair color modifications. The histological changes in the studied group that were treated with $20 \mathrm{mg} / \mathrm{kg}$ of isotretinoin every day consisted in a decrease in the numbers of the papillary projects of the endometrial tissue, stroma loss with thickness of the lining epithelium, fewer endometrial glands as a result of the resorption process of the embryo inside the uterus. The study concluded that systemic isotretinoin administered to pregnant mice induced toxicity to the embryo with resorption and alteration, as a result isotretinoin should definitely be avoided in the first post-implantation phase of gestation (39).

Regarding males, there are several studies that have analyzed the safety of isotretinoin treatment in reproductively active males. One study published in 2017 by Bispo et al on mice demonstrated few abnormalities found in both male reproductive organs and embryos. The study included mice that were treated with $1 \mathrm{mg} / \mathrm{kg} /$ day isotretinoin and were placed to mate with females after 10 days of treatment. The results showed that isotretinoin did not induce toxicity in males, but it did produce a decrease in the reproductive organs in weight and also in Sertoli and Leydig cell number. A decreased testosterone level was also identified. Regarding the embryos, the study outlined decreased fetal viability, increased resorption rate, post-implantation loss and visceral or skeletal malformations (40). On the other hand, a post-marketing surveillance study reported 13 pregnancies where the father was under treatment with acitretin. Among all 13 babies, only one had malformations which could not be associated with retinoid embryopathy. There were communicated six spontaneous abortions and the rest were reported as healthy neonates. The study was limited but the authors concluded that males under treatment of retinoids can plan fatherhood (41). The studies regarding the teratogenic effect of isotretinoin on reproductive males are still limited due to the unethical nature of these human studies; thus, further investigations should be performed.

\section{Apoptosis and teratogenicity}

Scientists have conducted studies showing the severe teratogenic effects since isotretinoin was introduced on the market, both in laboratory animals and humans (36). In humans, malformations induced by isotretinoin includes cranio-facial malformations, cardiac, thymic and central nervous abnormalities, but the commonest are microtia, anotia, micrognathia, aortic arch or heart defects, thymic ectopia or aplasia or cerebellar vermis agenesis (42-44). Thse malformations can be explained by the massive cell death that occurs in vertebrates during neural development and due to the fact that apoptosis is a contributor to nervous system development that requires a proper apoptotic signaling during embryogenesis $(45,46)$. ATRA is responsible for inducing reprogramming of cranial neural crest gene expression with increased apoptosis secondly $(47,48)$. Studies conducted on animals have confirmed that isotretinoin administration during pregnancy can increase the apoptosis of neural crest cells and the appearance of malformations (49-52). Malformations are caused by excessive cell death limited to trigeminal ganglion neuroblasts during ganglion formation. These are proposed by studies on mice which concluded that increased cell apoptosis is the principal mechanism involved in cranio-facial malformations induced by isotretinoin administration (53).

Another teratogenic effect of this drug is represented by heart defects and aortic arch malformations. These abnormalities can be explained by impaired migrations of neural crest cells. It is well known that morphogenesis and the development of cardiovascular tissue depend on coordinated regulation of cell proliferation and apoptosis (54). ATRA action on 
cardiovascular tissue is specific during early development, such as anteroposterior patterning of the heart or endocardial cushion formation (55-58). All of these data outline that neural crest cell apoptosis plays an essential role in the teratogenicity induced by isotretinoin treatment.

\section{Conclusions}

According to the US-FDA, isotretinoin is the first line of treatment for severe acne vulgaris causing a reduction in sebum production, acne lesions and acne scarring. It has limited indications in the case of non-nodular, inflammatory acne, where the administration of isotretinoin is recommended to patients with psychological distress caused by prolonged acne lesions (38). It also has shown efficiency in reducing anxiety and depression caused by the aesthetic aspect of the skin affected by acne vulgaris. This treatment has demonstrated effectiveness to clear most superficial or deep inflammatory nodules.

There is sufficient data to support the major action of isotretinoin is human sebocyte apoptosis. In addition, other cells such as neural crest cells or neural crest-derived neuroblastoma cells are very susceptible to isotretinoin-induced apoptosis. This mechanism is the base for numerous side effects induced by isotretinoin of which the most cited and significant is teratogenicity.

There are numerous studies that have aimed to analyze the teratogenic effect induced by isotretinoin treatment in women during embryogenesis, showing the possible congenital malformations that may occur. In recent years, research has focused on the study of the possible side effects of isotretinoin in fertile men, without clear data to date.

\section{Acknowledgements}

Not applicable.

\section{Funding}

Not funding was received.

\section{Availability of data and materials}

The information included in this review is documented by relevant literature data.

\section{Authors' contributions}

FS was involved in the writing of the manuscript and in conception of the review. CCD analyzed and wrote the mechanism of action of isotretinoin. RCP analyzed the data from the literature regarding the teratogenic effect of isotretinoin on fertile males and contributed to the writing of the manuscript. AP analyzed the teratogenic effect on fertile women and was responsible for the writing of the relevant section. RGM analyzed the apoptosis effect of isotretinoin in inducing teratogenicity and wrote the relevant section of the manuscript. MCD is the corresponding author and was also involved in the conception and design of the review, and contributed in the writing of the manuscript. All authors critically revised the manuscript and approved the final version of the manuscript to be published.

\section{Ethics approval and consent to participate}

Not applicable.

\section{Patient consent for publication}

Not applicable.

\section{Competing interests}

The authors declare that they have no competing interests.

\section{References}

1. Forbat E, Ali FR and Al-Niaimi F: Dermatological indications for the use of isotretinoin beyond acne. J Dermatolog Treat 29: 698-705, 2018 .

2. https://en.wikipedia.org/wiki/Isotretinoin\#History.

3. Honein MA, Lindstrom JA and Kweder SL: Can we ensure the safe use of known human teratogens? The iPLEDGE test case. Drug Saf 30: 5-15, 2017.

4. Prevost $\mathrm{N}$ and English JC: Isotretinoin: Update on controversial issues. J Pediatr Adolesc Gynecol 26: 290-293, 2013.

5. Jajoria H and Mysore V: Washout period for pregnancy post isotretinoin therapy. Indian Dermatol Online J 11: 239-242, 2020.

6. Tsukada M, Schröder M, Roos TC, Chandraratna RA, Reichert U, Merk HF, Orfanos CE and Zouboulis CC: 13 -cis retinoic acid exerts its specific activity on human sebocytes through selective intracellular isomerization to all-trans retinoic acid and binding to retinoid acid receptors. J Invest Dermatol 115: 321-327, 2000.

7. Melnik BC: Apoptosis may explain the pharmacological mode of action and adverse effects of isotretinoin, including teratogenicity. Acta Derm Venereol 97: 173-181, 2017.

8. Nelson AM, Gilliland KL, Cong Z and Thiboutot DM: 13-cis Retinoic acid induces apoptosis and cell cycle arrest in human SEB-1 sebocytes. J Invest Dermatol 126: 2178-2189, 2006.

9. Nelson AM, Cong Z, Gilliland KL and Thiboutot DM: TRAIL contributes to the apoptotic effect of 13-cis retinoic acid in human sebaceous gland cells. Br J Dermatol 165: 526-533, 2011.

10. Nelson AM, Zhao W, Gilliland KL, Zaenglein AL, Liu W and Thiboutot DM: Neutrophil gelatinase-associated lipocalin mediates 13-cis retinoic acid-induced apoptosis of human sebaceous gland cells. J Clin Invest 118: 1468-1478, 2008.

11. Kelhälä HL, Fyhrquist N, Palatsi R, Lehtimäki S, Väyrynen JP, Kubin ME, Kallioinen M, Alenius H, Tasanen K and Lauerma A: Isotretinoin treatment reduces acne lesions but not directly lesional acne inflammation. Exp Dermatol 25: 477-478, 2016.

12. MacFarlane M: TRAIL-induced signaling and apoptosis. Toxicol Lett 139: 89-97, 2003.

13. Zhang X, Tang N, Hadden TJ and Rishi AK: Akt, FoxO and regulation of apoptosis. Biochim Biophys Acta 1813: 1978-1986, 2011.

14. Modur V, Nagarajan R, Evers BM and Milbrandt J: FOXO proteins regulate tumor necrosis factor-related apoptosis inducing ligand expression. Implications for PTEN mutation in prostate cancer. J Biol Chem 277: 47928-47937, 2002.

15. Melnik BC and Zouboulis CC: Potential role of FoxO1 and mTORC1 in the pathogenesis of Western diet-induced acne. Exp Dermatol 22: 311-315, 2013.

16. Mirdamadi Y, Thielitz A, Wiede A, Goihl A, Papakonstantinou E, Hartig R, Zouboulis CC, Reinhold D, Simeoni L, Bommhardt $\mathrm{U}$, et al: Insulin and insulin-like growth factor-1 can modulate the phosphoinositide-3-kinase/Akt/FoxO1 pathway in SZ95 sebocytes in vitro. Mol Cell Endocrinol 415: 32-44, 2015.

17. Agamia NF, Abdallah DM, Sorour O, Morad B and Younan DY: Skin expression of mammalian target of rapamycin and forkhead box transcription factor O1, and serum insulin-like growth factor-1 in patients with acne vulgaris and their relationship with diet. Br J Dermatol 174: 1299-1307, 2016.

18. Sørensen K, Aksglaede L, Petersen JH, Andersson AM and Juul A: Serum IGF1 and insulin levels in girls with normal and precocious puberty. Eur J Endocrinol 166: 903-910, 2012. 
19. Melnik BC: Diet in acne: Further evidence for the role of nutrient signaling in acne pathogenesis. Acta Derm Venereol 92: 228-231, 2012.

20. Gross DN, Wan M and Birnbaum MJ: The role of FOXO in the regulation of metabolism. Curr Diab Rep 9: 208-214, 2009.

21. Wang Y, Zhou Y and Graves DT: FOXO transcription factors: Their clinical significance and regulation. Biomed Res Int 2014: 925350, 2014.

22. Gudas LJ and Wagner JA: Retinoids regulate stem cell differentiation. J Cell Physiol 226: 322-330, 2011.

23. Kim MJ, Ahn K, Park SH, Kang HJ, Jang BG, Oh SJ, Oh SM, Jeong YJ, Heo JI, Suh JG, et al: SIRT1 regulates tyrosine hydroxylase expression and differentiation of neuroblastoma cells via FOXO3a. FEBS Lett 583: 1183-1188, 2009.

24. Sakoe Y, Sakoe K, Kirito K, Ozawa K and Komatsu N: FOXO3A as a key molecule for all-trans retinoic acid-induced granulocytic differentiation and apoptosis in acute promyelocytic leukemia Blood 115: 3787-3795, 2010.

25. Van Der Heide LP, Hoekman MF and Smidt MP: The ins and outs of FoxO shuttling: Mechanisms of FoxO translocation and transcriptional regulation. Biochem J 380: 297-309, 2004.

26. Baxter RC: Nuclear actions of insulin-like growth factor binding protein-3. Gene 569: 7-13, 2015.

27. Schedlich LJ, Graham LD, O'Han MK, Muthukaruppan A, Yan X, Firth SM and Baxter RC: Molecular basis of the interaction between IGFBP-3 and retinoid X receptor: Role in modulation of RAR-signaling. Arch Biochem Biophys 465: 359-369, 2007.

28. Liu B, Lee HY, Weinzimer SA, Powell DR, Clifford JL, Kurie JM and Cohen P: Direct functional interactions between insulin-like growth factor-binding protein-3 and retinoid $X$ receptor-alpha regulate transcriptional signaling and apoptosis. J Biol Chem 275: 33607-33613, 2000.

29. Cyrulnik AA, Viola KV, Gewirtzman AJ and Cohen SR High-dose isotretinoin in acne vulgaris: Improved treatment outcomes and quality of life. Int J Dermatol 51: 1123-1130, 2012.

30. https://www.dermatologyadvisor.com/home/topics/acne/comparisonof-acne-treatment-protocols-with-isotretinoin/. Accessed May 28 2020.

31. American Academy of Dermatology Association. Acne Clinical Guideline. https://www.aad.org/practicecenter/quality/clinicalguidelines/acne/isotretinoin.

32. Henry D, Dormuth C, Winquist B, Carney G, Bugden S, Teare G Lévesque LE, Bérard A, Paterson JM and Platt RW; CNODES (Canadian Network for Observational Drug Effect Studies) Investigators: Occurrence of pregnancy and pregnancy outcomes during isotretinoin therapy, CMAJ 188: 723-730, 2016.

33. Simin MK and Nagesh M: Pregnancy prevention programs for medications used in dermatology. J Skin Sex Transm Dis 2: $18-25,2020$

34. Brinker A, Kornegay $\mathrm{C}$ and Nourjah P: Trends in adherence to a revised risk management program designed to decrease or eliminate isotretinoin-exposed pregnancies: Evaluation of the accutane SMART program. Arch Dermatol 141: 563-569, 2005.

35. Cheetham TC, Wagner RA, Chiu G, Day JM, Yoshinaga MA and Wong L: A risk management program aimed at preventing fetal exposure to isotretinoin: Retrospective cohort study. J Am Acad Dermatol 55: 442-448, 2006.

36. Shin J, Cheetham TC, Wong L, Niu F, Kass E, Yoshinaga MA, Sorel M, McCombs JS and Sidney S: The impact of the iPLEDGE program on isotretinoin fetal exposure in an integrated health care system. J Am Acad Dermatol 65: 1117-1125, 2011.

37. Tkachenko E, Singer S, Sharma P, Barbieri J and Mostaghimi A: US food and drug administration reports of pregnancy and pregnancy-related adverse events associated with isotretinoin. JAMA Dermatol 155: 1175-1179, 2019.
38. Layton AM, Dreno B, Gollnick HP and Zouboulis CC: A review of the European Directive for prescribing systemic isotretinoin for acne vulgaris. J Eur Acad Dermatol Venereol 20: 773-776, 2006.

39. Salih LA: Histological study of the isotretinoin drug effect on the intrauterine prenatal development in the pregnant mice. Iraqi J Sci 58: 1601-1608, 2017.

40. Bispo ACC, Galvão TC, Tamoyese VM, Costa GA, Ramos SP and Salles MJS: Effects of isotretinoin on the reproduction of pubertal male mice and malformations in the offspring. Am J Biomed Sci 9: 225-236, 2017

41. Kumar P, Das A, Lal NR, Jain S and Ghosh A: Safety of important dermatological drugs (retinoids, immune suppressants, anti androgens and thalidomide) in reproductively active males with respect to pregnancy outcome: A brief review of literature. Indian J Dermatol Venereol Leprol 84: 539-546, 2018.

42. Coberly S, Lammer E and Alashari M: Retinoic acid embryopathy: Case report and review of literature. Pediatr Pathol Lab Med 16: 823-836, 1996

43. Lammer EJ, Chen DT, Hoar RM, Agnish ND, Benke PJ, Braun JT, Curry CJ, Fernhoff PM, Grix AW Jr, Lott IT, et al: Retinoic acid embryopathy. N Engl J Med 313: 837-841, 1985.

44. Lynburg MC, Khoury MJ, Lammer EJ, Waller KO, Codero JF and Erickson JD: Sensitivity, specificity, and positive predictive value of multiple malformations in isotretinoin embryopathy surveillance. Teratology 42: 513-519, 1990.

45. Fernhoff PM and Lammer EJ: Craniofacial features of isotretinoin embryopathy. J Pediatr 105: 595-597, 1984.

46. Miura M: Apoptotic and non-apoptotic caspase functions in neural development. Neurochem Res 36: 1253-1260, 2011.

47. Yamaguchi Y and Miura M: Programmed cell death in neurodevelopment. Dev Cell 32: 478-490, 2015.

48. Smith SM, Garic A, Flentke GR and Berres ME: Neural crest development in fetal alcohol syndrome. Birth Defects Res C Embryo Today 102: 210-220, 2014.

49. Williams SS, Mear JP, Liang HC, Potter SS, Aronow BJ and Colbert MC: Large-scale reprogramming of cranial neural crest gene expression by retinoic acid exposure. Physiol Genomics 19: 184-197, 2004

50. Wang L, Mear JP, Kuan CY and Colbert MC: Retinoic acid induces CDK inhibitors and growth arrest specific (Gas) genes in neural crest cells. Dev Growth Differ 47: 119-130, 2005.

51. Johnston MC and Bronsky PT: Animal models for human craniofacial malformations. J Craniofac Genet Dev Biol 11: 277-291, 1991.

52. Watanabe T, Goulding EH and Pratt RM: Alterations in craniofacial growth induced by isotretinoin (13-cis-retinoic acid) in mouse whole embryo and primary mesenchymal cell culture. J Craniofac Genet Dev Biol 8: 21-33, 1988.

53. Lammer EJ and Armstrong DL: Malformations in hindbrain structures among humans exposed to isotretinoin (13-cis-retinoic acid) during early embryogenesis. In: Retinoids in Normal Development and Teratogenesis. Morriss-Kay G (ed). Oxford University Press, New York, pp281-295, 1991.

54. Shuler CF: Programmed cell death and cell transformation in craniofacial development. Crit Rev Oral Biol Med 6: 202-217, 1995.

55. Fisher SA, Langille BL and Srivastava D: Apoptosis during cardiovascular development. Circ Res 87: 856-864, 2000

56. Pan J and Baker KM: Retinoic acid and the heart. Vitam Horm 75: 257-283, 2007.

57. Xavier-Neto J, Rosenthal N, Silva FA, Matos TG, Hochgreb T and Linhares VL: Retinoid signaling and cardiac anteroposterior segmentation. Genesis 31: 97-104, 2001

58. Niederreither K, Vermot J, Messaddeq N, Schuhbaur B, Chambon P and Dollé P: Embryonic retinoic acid synthesis is essential for heart morphogenesis in the mouse. Development 128: 1019-1031, 2001 